\title{
Otomatik Üretim Teknolojisine Uygun Betonların Basınç Dayanımlarının Makine Öğrenmesi Yöntemiyle Belirlenmesi
}

\author{
Nihan Kazak Çerçevik $^{1 *}$, Hüseyin Kayhan ${ }^{2}$ \\ 1* Bilecik Şeyh Edebali Üniversitesi, Mühendislik Fakültesi, Bilgisayar Mühendisliği Bölümü, Bilecik, Türkiye, (ORCID: 0000-0001-5339-0055), \\ nihan.kazak@bilecik.edu.tr \\ ${ }^{2}$ Bilecik Şeyh Edebali Üniversitesi, Mühendislik Fakültesi, Bilgisayar Mühendisliği Bölümü, Bilecik, Türkiye, (ORCID: 0000-0001-5585-8993), \\ hkayhann@gmail.com
}

(International Conference on Design, Research and Development (RDCONF) 2021 - 15-18 December 2021)

(DOI: $10.31590 /$ ejosat.1041528)

ATIF/REFERENCE: Kazak Çerçevik N. \& Kayhan H. (2021). Otomatik Üretim Teknolojisine Uygun Betonların Basınç Dayanımlarının Makine Öğrenmesi Yöntemiyle Belirlenmesi. Avrupa Bilim ve Teknoloji Dergisi, (32), 728-735.

$\ddot{O} \mathbf{z}$

Beton, yapı malzemeleri arasında mekanik özellikleri en karmaşık kompozitlerin başında gelmektedir. Betonun en temel mekanik özelliği ise basınç dayanımıdır. Betonarme yapılarda betonun basınç dayanımını hızlı, doğru, maliyetsiz ve zahmetsizce belirlemek oldukça önemli bir hedeftir. Bu çalışmada, beton basınç dayanımı belirtilen amaçlar göz önünde bulundurularak görüntü işleme ve makine öğrenmesi yöntemleri ile tahmin edilmektedir. Önerilen yöntemde uygulama yapılabilmesi için otomatik üretim teknolojisine uygun 48 adet küp numune hazırlanmıştır. Hazırlanan beton numunelerinde uçucu kül ve lif değişkenlerinin oluştuğu 6 farklı beton tipi kullanılmıştır. Beton numunelerinden elde edilen görüntüler ilk olarak ön işlem adımlarından geçerek veriseti hazırlanmıştır. Sonraki aşamada, beton görüntülerinin öznitelikleri Gri Seviye Eş Oluşum Matrisi (GLCM) yöntemi kullanılarak çıkarılmıştır. Elde edilen öznitelikler içinden rasgele seçilen \%80'i eğitim, geri kalanı ise test seti olarak belirlenmiştir. Son adımda ise, K-En Yakın Komşu (KNN) algoritması uygulanarak betonda kullanılan malzemelerin değişimi ile beton basınç dayanımı ve görüntülerinde oluşan farklılıklar araştırılmıştır. Önerilen yöntem $100 \mathrm{kez}$ tekrarlanarak doğruluk oranlarının ortalaması alınmıştır. Bulunan sonuçlar otomatik üretim teknolojisine uygun beton görüntüleri ile basınç dayanımı arasında \%79.7'lik başarım oranı sağlanmıştır. Bu sayede gelişimini her geçen gün artıran otomatik üretim teknolojisine uygun yapıların betonun en önemli mekanik özelliklerinden biri olan basınç dayanımı tahminleri, görüntüler üzerinden yapılabileceği ortaya konulmuştur.

\section{Determination of Compressive Strength of Concretes Suitable for Automatic Production Technology by Machine Learning Method}

\begin{abstract}
Concrete is one of the most complex composites with mechanical properties among building materials. The most basic mechanical property of concrete is compressive strength. It is a very important goal to determine the compressive strength of concrete in reinforced concrete structures quickly, accurately, inexpensively and effortlessly. In this study, concrete compressive strength is estimated by image processing and machine learning methods, taking into account the mentioned purposes. In order to be able to apply the proposed method, 48 cube samples were prepared in accordance with automatic production technology. In the prepared concrete samples, 6 different concrete types were used in which fly ash and fiber variables were formed. The images obtained from the concrete samples were first prepared by going through the preprocessing steps. In the next step, the features of the concrete images were extracted using the Gray Level Co-occurrence Matrix (GLCM) method. Of the features obtained, $80 \%$ randomly selected were determined as training and the rest as test set. In the last step, by applying the K-Nearest Neighbor (KNN) algorithm, the changes in the materials used in the concrete and the differences in the concrete compressive strength and appearance were investigated. The proposed method was repeated 100 times and the average of the accuracy rates was taken. The results obtained showed a accuracy
\end{abstract}

* Sorumlu Yazar: nihan.kazak@ bilecik.edu.tr 
rate of $79.7 \%$ between the concrete images suitable for automatic production technology and the compressive strength. In this way, it has been revealed that the pressure strength estimations, which is one of the most important mechanical properties of concrete, can be made through images of structures suitable for automatic production technology, which increases its development day by day.

Keywords: Machine Learning, Image Processing, Mechanical Properties, 3D Concrete.

\section{Giriş}

Makine öğrenmesi kural tabanlı programlamaya dayanmadan, sunulan verilerden bir öğrenim sağlayabilen ve bu öğrenim sayesinde yapay zeka yardımıyla çıkarımlar yaparak sonuç üretebilen veri analizi tekniğidir. Son yıllardaki ulaşılabilir verilerin hızlı bir şekilde artması, problem çözme için yapay zeka kullanımında verinin rolünü de değiştirmiştir. Verilerin artmasıyla beraber makine öğrenmesi görüntü işleme, nesne tanıma, ses tanıma, tıp, ulaşım, pazarlama, otomotiv, insan kaynakları, satış, finans, eğlence, gibi birçok alanda kullanılmaktadır (Chang, Cohen and Ostdiek, 2018).

Görüntü işleme, son dönemde birçok alanda başarılı bir şekilde uygulanmaktadır. Görüntüden anlamlı özelliklerin çıkarılması ile birlikte makine öğrenmesi kullanılarak yüz tanıma, obje tanıma, görüntü tahmin etme, duygu tanıma, yaş tahmini, kilo tahmini, hastalık teşhisi vb. gibi problemler yüksek başarım oranları ile çözüme kavuşturulmuştur (Wiley and Lucas, 2018).

Otomatik yapı teknolojisi, klasik yapı üretim basamaklarını azaltarak bilgisayar destekli sistematik üretime olanak sağlamak amacı ile tasarlanmıştır. Bu teknoloji sayesinde kalıp, demir ve beton işçiliği oldukça azaltılmış maliyetlerin düşürülmesi sağlanmıştır. Sürekli ve esnek üretim yetenekleri ile gelecekte yap1 üretiminin bu teknoloji ile yapılacağı öngörülmektedir (Behrokh Khoshnevis, 2004).

Çalışma kapsamında makine öğrenmesi, ileri bir beton teknolojisi olan otomatik üretime uygun betonların dayanımını tahmin etmek amacı ile kullanılmıştır. Betonun görüntü işleme yöntemleri kullanılarak tahribatsız basınç dayanım tahmini yapan birçok çalışma bulunmaktadır. $\mathrm{Bu}$ yöntemler, genellikle beton içeriğinde bulunan agrega, çimento hamuru ve boşlukların arasında bir korelasyon sayesinde tahminler önermektedir (Özen, 2007). Yapılan çalışmalarda kullanılan beton tipleri klasik beton tipleri olup agrega gradasyonları büyük dane çapları içermektedir. Ancak otomatik üretimli betonların makine ağzından (nozzle) çıkış yapabilmesi ve katmanlı üretime uygun olması için düşük dane çaplı bir gradasyona sahip olması gerekmektedir. Agrega gradasyonun düşük dane çaplı olması da görüntüden basınç dayanımı tahminini güçleştirmektedir. $\mathrm{Bu}$ güçlüğü ortadan kaldırmak için bu çalışma kapsamında sınıflama performansı yüksek makine öğrenmesi tekniklerinin kullanıldığ bir yöntem önerilmiştir.

\subsection{Makine Öğrenmesi ve Görüntü İşleme}

Makine öğrenmesi eğitim amacı ile sisteme verilen ilk veri setleri ile başlar. Tasarlanan algoritma, ilk verileri kullanarak öğrenim sağlar. Öğrenim amacı ile kullanılan algoritmanın yeterliliği verilen ilk verilerin sonuçları ile karşılaştırılarak belirlenir. Yeterli öğrenim sonuçları elde edilmişse tasarlanan öğretim algoritması uygundur. Öğrenim yeterli değilse algoritmanın öğretim kapasitesi artırılarak makine öğrenme yönteminin yeterliliği sağlanır (Mahesh, 2020).
Ses, görüntü ve belge inceleme alanlarındaki ilerleme makine öğrenmesi kullanımıyla mümkün olmaktadır. Görüntü inceleme alanı; dijital görüntü işleme, nesne tanıma, yüz tanıma, desen tanıma, optik karakter tanıma ve kod tanıma gibi teknolojileri barındırmaktadır (Ayata, 2020). Görüntü işleme tekniklerinin kapasitelerinin artması ile daha çok alanda kullanımı yaygınlaşmaktadır. $\mathrm{Bu}$ alanlardan bir tanesi de yapı mühendisliği yapılarıdır. Görüntü işleme yapı mühendisliğinde beton yapı çatlakları (Yamaguchi and Hashimoto, 2009), betonarme yapı sağlığı izleme (Nazmul and Matsumoto, 2008) ve altyapı elemanları kontrolleri (Sinha and Fieguth, 2006) gibi birçok alanda araştırılmış, oldukça yeterli sonuçlar elde edilmiştir.

\subsection{Otomatik Üretimli Beton Teknolojisi}

Eklemeli üretim yöntemlerinden olan otomatik üretimli modellerin katmanların üst üste dökülerek tasarlanan modelin ortaya çıkması felsefesine dayanmaktadır. İstenilen modellerin bilgisayar altyapısı kullanılarak uygun parçalanarak ayrılması, sonrasında ise bu parçaların üretimleri ile tüm modelin ortaya çıkarılması ile hızlı esnek ve devamlı üretim amaçları yerine getirilmektedir. Sağlanan bu avantajlar ile eklemeli üretim teknolojisi özellikle son 30 yılda çık hılı bir gelişim yaşamaktadır. 2020 yılında eklemeli üretim teknolojilerinin market değerinin 21 milyar ABD doları büyüklüğüne ulaştığ1 tahmin edilmektedir (Gibson, Rosen and Stucker, 2015; Gul et al., 2018; LaMonica, 2013; Parmar, Khan, Tucci, Umer and Carlone, 2021; Thompson et al., 2016).

Eklemeli üretim sağladığı faydalar ile yap1 sektörüne de hızlı girmiştir. Öncelikle NASA'nın Dünya dışı gezegenlerde kolonileşme hedefini gerçekleştirmek için eklemeli üretim tekniklerini kullanma fikri ortaya çıkmıştır (B. Khoshnevis, Carlson, Leach and Thangavelu, 2012; Behrokh Khoshnevis, Thangavelu, Yuan and Zhang, 2013; Leach, Carlson, Khoshnevis and Thangavelu, 2012; Toklu and Çerçevik, 2017). Öncülleri Dünya dışı barınma ihtiyacını karşılayacak olsa da sağladığı avantajlar ve gelişimi ile otomatik üretimli yapı teknolojisinin konveksiyonel yapılarda kullanımı her geçen gün artmaktadır. $\mathrm{Bu}$ artıştaki önemli unsurların başında işçiliğin ve dolayısı ile maliyetlerin ciddi oranda azalmasidır (Akhnoukh, 2020; Hager, Golonka and Putanowicz, 2016; Khorramshahi and Mokhtari, 2017; Behrokh Khoshnevis, Hwang, Yao and Yeh, 2006; Zhang and Khoshnevis, 2013).

Sağladığı faydalar ile kullanımı hızla artan otomatik yapı üretim teknolojisi pek çok açıdan araştırma geliştirme konusu olmaya devam etmektedir. Yapılan araştırmalar arasında mimari (Sousa et al., 2016), çelikle güçlendirilme (Mechtcherine et al., 2018), köprü tipi yapılar (Salet, Ahmed, Bos and Laagland, 2018), yangına dayanım (Kruger et al., 2020), seramik katkılı tasarım (Shirooyeh et al., 2015), beton karışım tipleri (Kazemian, Yuan, Cochran and Khoshnevis, 2017; Toklu, Çerçevik and Şahinöz, 2016) gibi pek çok konu bulunmaktadır. 


\subsection{Betonda Tahribatsız Basınç Dayanım Tahmini}

Beton içinde birden çok malzeme bulunan kompozit bir tasarımdır. Betonarme yapılar için kullanım bölgeleri genellikle elemanların basınca maruz kalan bölgeleridir. $\mathrm{Bu}$ da betonun basınç dayanımını, en önemli mekanik özelliklerinden biri haline getirmektedir. Betonun basınç dayanımı, basınç test cihazı ile deney yaparak tahribatlı şekilde belirlenebilir ya da betonun bütünlüğünü bozmadan olduğu yerde tahribatsız bir şekilde tahmin edilebilir (Kabay and Aköz, 2003).

Tahribatsız deney yöntemleri arasında beton test çekici, ultrasonik yöntemler, penetrasyon yöntemleri, resonant frekans yöntemleri gibi yöntemler bulunmaktadır (Breysse, 2012). Bu yöntemler tahribatlı yöntemler gibi batonun basınç dayanımını tam olarak vermese bile yakın basınç dayanımı sonuçları verebilmektedir. Ancak bu yöntemler özel cihazlar ve tecrübe isteyen yaklaşık değerler bulan yöntemlerdir. Tahribatsız deney yöntemleri teknolojinin gelişimi ile her geçen gün hızla gelişmekte farklı metotlar ortaya konulmaktadır. $\mathrm{Bu}$ yöntemlerden bir tanesi de beton görüntüleri kullanılarak betonun basınç dayanımının tahmin edilmesidir.

\subsubsection{Beton Görüntüleri Kullanılarak Beton Basınç Dayanım Tahmini}

Tahribatsız beton testleri kategorisine giren görüntüden basınç dayanım tahmini son dönemde hızlı ve pratik kullanım imkânları sayesinde pek çok araştırmacı tarafından araştırılmıştır. Yapılan bu araştırmalar irdelendiğinde, çalışmaların farklı görüntü işleme teknikleri ile geleneksel beton tiplerine üzerine yoğunlaştığı görülmektedir.

Beton görüntüsünden basınç dayanımı yapmak için makine öğrenmesi metotlarından Gri Seviye Eş Oluşum Matrisi (Li et al., 2016) K-En Yakın Komşu (Kang, Yoo and Gupta, 2021) derin öğrenme (Flah, Suleiman and Nehdi, 2020; Kim, Kawamura, Nakamura and Tarighat, 2020) gibi metotlar kullanılmıştır.

\section{Materyal ve Metot}

Bu bölümde, otomatik üretim teknolojisine uygun betonların dayanımlarını tahmin etme süreci analiz edilmektedir. Çalışmanın algoritması Şekil 1'de sunulmaktadır.

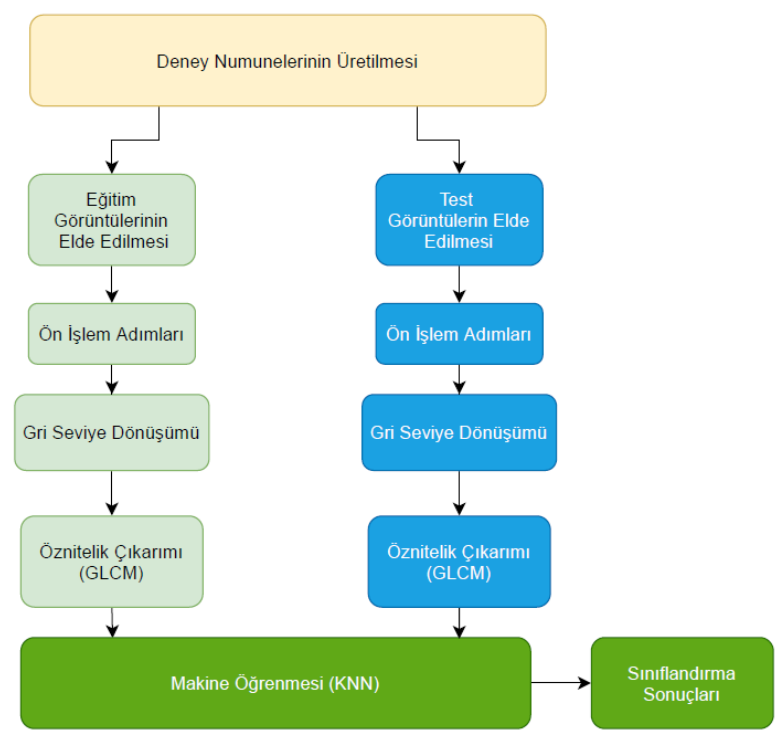

Şekil 1. Çalışmanın Akış Şeması
Algoritma, beton numunelerinin elde edilmesi ile başlar. Daha sonra numuneler görüntülenerek, ön işlem adımlarından geçerek görüntü veri seti hazırlanır. GLCM yöntemi kullanılarak öznitelik çıkarma süreci tamamlanır. Ardından KNN yöntemi ile basınç dayanım tahminleri yapılarak sınıflandırma gerçekleştirilir.

\subsection{Deney Numunelerinin Üretilmesi}

Önerilen yöntemin makine öğrenmesi ile eğitimi ve test çalışmalarını yapabilmek amacı ile otomatik yapı üretimine uygun 48 adet $10 \times 10 \times 10 \mathrm{~cm}$ küp numune hazırlanmıştır. Hazırlanan numunelerin malzeme karışım oranları daha önce yapılmış bir çalışmadan (Toklu et al., 2016) alınmıştır. Beton karışım oranları Tablo 1'de verilmiştir. Örnek alınan otomatik üretime uygun beton karışımlarında $42.5 \mathrm{R}$ tipi çimento, 0-2 mm dane dağılımına sahip BG-002 kirli beyaz flux kalsine edilmiş diatomit, 2-4 mm dağılımına sahip doğal agrega, 380-650 MPa dayanıma sahip polipropilen lif, Tunçbilek termik santralinden elde edilmiş uçucu kül ve şehir suyu kullanılmıştır. Otomatik yapı üretim teknolojisine uygun bir taze beton örneği Şekil 2'de sunulmuştur.

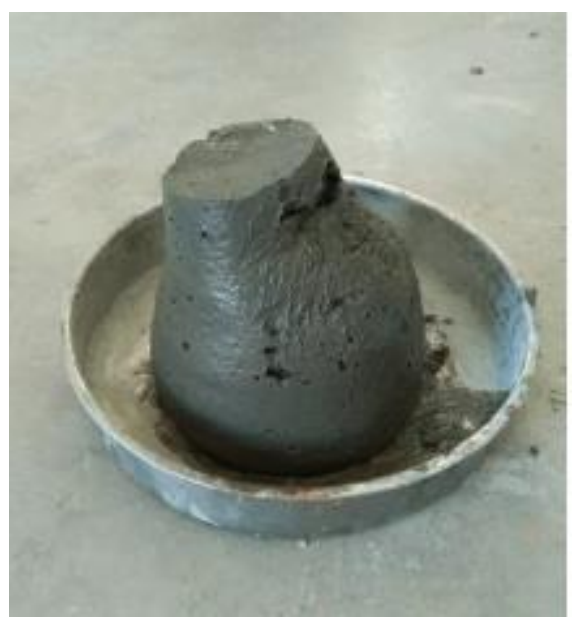

Şekil 2. Otomatik Yapı Üretimine Uygun Taze Beton Örneği.

Otomatik beton üretimine uygun hazırlanan beton numunelerinde değişken parametreler olarak uçucu kül ve polipropilen lif miktarı değişken olarak belirlenmiştir. Uçucu kül ikameli karışımlarda eklenen uçucu kül miktarı kadar çimento azaltılarak uçucu külün beton basınç dayanımına etkisi sağlanmıştır. Polipropilen lif ise hazırlanan eğitim ve test setlerinin yarısına eklenilmemiş diğer yarısına ise sabit miktarda eklenmiştir (Tablo 1).

Beton karışımları laboratuvar betoniyeri kullanılarak TS 1247 'e uygun şekilde hazırlanmış, temiz bir yağ ile yağlanmış $10 \times 10 \times 10 \mathrm{~cm}$ küp kalıplara dökülerek kalıba yerleşmeleri sağlanmıştır (TS 1247, 2018). 24 saat sonra kalıplardan alınan $\begin{array}{llllll} & \text { numuneler } & 22 & \pm 1 & { }^{\circ} \mathrm{C} & \text { sicaklığındaki kür havuzuna }\end{array}$ yerleştirilmiştir. Kür havuzunda 7 gün bekletilen numuneler kurumalarından sonra fotoğraflama işlemine geçilmiştir (Şekil $3)$. 


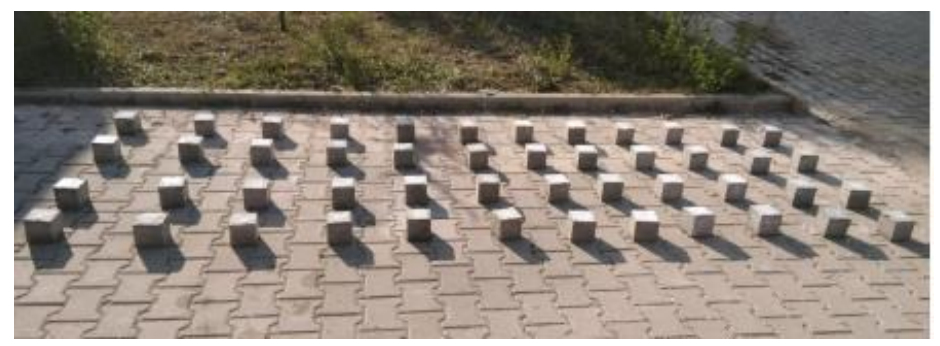

Şekil 3. Eğitim ve Test Çalışmalarında Kullanılacak Küp Beton Numuneler

Tablo 1. Çalışmada Kullanılan Beton Eğitim ve Test Deney Seti Karışım Oranları $\left(\mathrm{kg} / \mathrm{m}^{3}\right)$

\begin{tabular}{ccccccccc}
\hline $\begin{array}{c}48 \text { Adet Küp } \\
\text { Numune }\end{array}$ & $\begin{array}{c}\text { Numune } \\
\text { Kodu }\end{array}$ & $\begin{array}{c}\text { Numune } \\
\text { Sayısı }\end{array}$ & $\begin{array}{c}\text { Çimento } \\
\text { Dozajı }\end{array}$ & Agrega & Diatomit & Su & $\begin{array}{c}\text { Uçucu } \\
\text { Kül }\end{array}$ & $\begin{array}{c}\text { Polipropilen } \\
\text { Lif }\end{array}$ \\
\hline 1. Grup & U0L0 & 8 & 580 & 400 & 300 & 460 & 0 & 0 \\
2. Grup & U1L0 & 8 & 554 & 400 & 300 & 460 & 26 & 0 \\
3. Grup & U2L0 & 8 & 528 & 400 & 300 & 460 & 52 & 0 \\
\hline 4. Grup & U0L1 & 8 & 580 & 400 & 300 & 460 & 0 & 3 \\
5. Grup & U1L1 & 8 & 554 & 400 & 300 & 460 & 26 & 3 \\
6. Grup & U2L1 & 8 & 528 & 400 & 300 & 460 & 52 & 3 \\
\hline
\end{tabular}

\subsection{Numune Görüntülerinin Elde Edilmesi}

Numunelerin elde edilmesinden sonraki adım görüntü veri setinin oluşturulması adımıdır. Öncelikle görüntüleme yapabilmek amacıyla 1 şı kaynağı, tripod ve fotoğraf makinesinden oluşan bir düzenek kurulmuştur. Fotoğraf makinesi olarak Nikon-N90 marka model fotoğraf makinasından faydalanılmıştır. Bu makine 12 MP çözünürlüklü 4288 x 2848 piksel çekim yapabilen bir makinadır. 48 adet beton küplerinin her birinin 4 yanal yüzü fotoğraflanarak toplamda 192 adet görüntüden oluşan bir veri seti elde edilmiştir.

\section{3. Ön İşlem Adımları}

Oluşturulan görüntü veri seti numune kodu ve yanal yüznumaraları kullanılarak etiketlenmiştir. Beton görüntülerinin arka plandan ayırt edilebilmesi amacıyla kırpma işlemi gerçekleştirilmiştir. Bu aşamadan sonra algoritmanın ilerleyen adımları için renkli görüntülerin gri seviye dönüşüm işlemleri tamamlanarak beton görüntü veri seti oluşturulmuştur. Şekil 4'te veri setinden örnek iki beton görüntüsü verilmiştir.
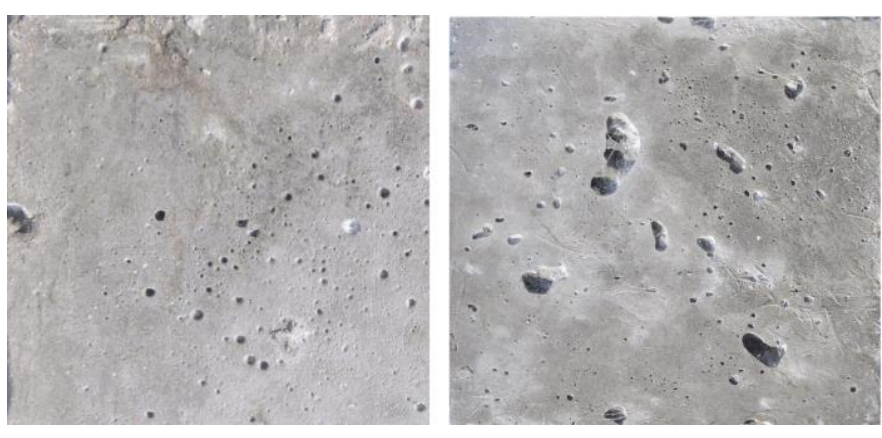

Şekil 4. Örnek Beton Numune Görüntüleri

\section{4. Öznitelik Çıkarımı}

Sonraki aşama görüntülerin özniteliklerinin çıkarım aşamasıdır. Bu aşamada öznitelik çıkartmak için Gri Seviye Eş Oluşum Matrisi (GLCM) yönteminden faydalanılmıştır. GLCM istatiksel doku analiz yöntemidir. Özellikle medikal görüntüler gibi doku analizinin ağırlıklı olduğu çalışmalarda kullanılır. GLCM, gri seviyeli bir görüntü verildiğinde görüntüde belirli bir değere ve ofset değerine sahip piksel çiftlerinin ne sıklıkla oluştuğunu hesaplar (Haralick, Dinstein and Shanmugam, 1973).

Doku analizi genellikle bir görüntünün rotasyonel olarak değişmeyen yönlerini saptar. Bunun için aynı ilişkiye karşılık gelen çeşitli açılarda döndürülen eş oluşum matrisleri hesaplanır ve ardından toplanılır. Şekil 5'te GLCM'nin çalışma mantığına bir örnek gösterilmiştir.

\begin{tabular}{|c|c|c|c|}
\hline 1 & 1 & 3 & 1 \\
\hline 2 & 4 & 1 & 2 \\
\hline 1 & 2 & 5 & 2 \\
\hline 3 & 5 & 1 & 3 \\
\hline
\end{tabular}

\begin{tabular}{|c|c|c|c|c|c|}
\hline & 1 & 2 & 3 & 4 & 5 \\
\hline 1 & & 2 & 2 & 0 & 0 \\
\hline 2 & 0 & 0 & 0 & 1 & 1 \\
\hline 3 & 1 & 0 & 0 & 0 & 1 \\
\hline 4 & 1 & 0 & 0 & 0 & 0 \\
\hline 5 & 1 & 1 & 0 & 0 & 0 \\
\hline
\end{tabular}

\section{Şekil 5. GLCM Örnek Çalışması}

Şekil 5 'te sol tarafta bir görüntüden kesit alınmıştır. Burada maksimum gri seviye değeri 5 olduğu için GLCM matrisi 5x5 boyutunda oluşturulmuştur. Görüntüdeki yatay komşu piksel değerleri eşlenerek, frekansı GLCM matrisine yazılmıştır. Örneğin $(1,2)$ piksel değerlerine sahip eşleniğin görüntü içerisinde 2 adet bulunmasından dolayı GLCM matrisindeki 1. Satır 2. Sütun 2 değerini almıştır. Bu yöntem ile görüntüden birçok öznitelik çıkarılabilir (Haralick et al., 1973). Bu çalışmada görüntünün kontrast, farklılık, homojenlik, enerji, korelasyon, açısal ikincil moment öznitelikleri kullanılmıştır. 


\subsection{K-En Yakın Komşu (KNN) Algoritması}

K-En Yakın Komşu (KNN) sınıflandırma algoritması olarak kullanımının yanında regresyon uygulamalarında da kullanılmaktadır. Eski bir yöntem olmasına rağmen kolay ve başarılı olması nedeniyle günümüzde hala yaygın olarak tercih edilmektedir.

KNN, denetimli makine öğrenme algoritmasıdır. KNN algoritması yeni vakaları tahmin etmek için etiketlenmemiş verilerin etiketlenmiş verilere benzerliğinden faydalanır. Yeni veriyi en çok benzeyen verilerin sınıfiyla işaretler. KNN her yeni gelen veri için tüm eğitim verilerini yeniden işler. Belirlenen $\mathrm{K}$ sayısı kadar en yakın komşuyu işaretler. En çok komşunun olduğu sınıfı yeni verinin sınıfı olarak işaretler ( $\mathrm{Du} \& \mathrm{Li}, 2019)$.

KNN algoritmasında mesafeyi belirlemek için çeşitli metrikler kullanılmaktadır. Bunlardan bazıları Manhattan mesafesi, Öklid mesafesi, Minkowski mesafesi ve Hamming mesafesidir.

Öklid mesafesi, bir noktanın Kartezyen koordinatı ve Kartezyen koordinatının transpoze edilmesi arasındaki farkları çarparak bulunur. Denklem 1'de Öklid mesafesi ölçümü gösterilmiştir.

$$
d_{(x, y)}=\sqrt{\sum_{i=1}^{n}\left(x_{i}-y_{i}\right)^{2}}
$$

Manhattan mesafesi, taksi mesafesi ya da blok mesafesi olarak da adlandırılmaktadır. İki nokta arasındaki uzaklık için Kartezyen koordinatların mutlak farklarını toplar. Denklem 2'de Manhattan mesafesi ölçümü için kullanılan denklem verilmiştir.

$$
d=\sum_{i=1}^{n}|X i-Y i|
$$

Minkowski mesafesi, $\mathrm{n}$ boyutlu gerçek uzayda iki nokta arasındaki mesafe ölçümüdür, Denklem 3'te verilmiştir. Manathan mesafesi ve Öklid mesafelerinin bir genellemesidir.

$$
d(X, Y)=\left(\sum_{i=1}^{n}\left|x_{i}-y_{i}\right|^{p}\right)^{\frac{1}{p}}
$$

Hamming mesafesi, iki ayrı ikili veri dizisini karşılaştırmak için kullanılan metriktir. Eşit uzunluktaki iki dizi karşılaştırılırken farklı olan bit konumlarının sayısını ölçmektedir. Hamming mesafesi Denklem 4 ile hesaplanmaktadır.

$$
d_{H}(a, b)=\neq\left\{j: a_{j} \neq b_{j}, j=0,1, \ldots, n-1\right\}
$$

\section{Araştırma Sonuçları ve Tartışma}

Görüntü işleme ve makine öğrenmesi ile beton basınç dayanımları tahmini için yapılan deneyler bu bölümde anlatılmaktadir.

\subsection{Beton Basınç Dayanımları}

Beton basınç deneyleri fotoğraflama sonrasında TS EN 12390-3'e uygun şekilde yapılarak belirlenmiştir. Her birinde 8 adet bulunan 6 farklı karışım setine göre ortalama basınç dayımları Şekil 6'da verilmiştir.

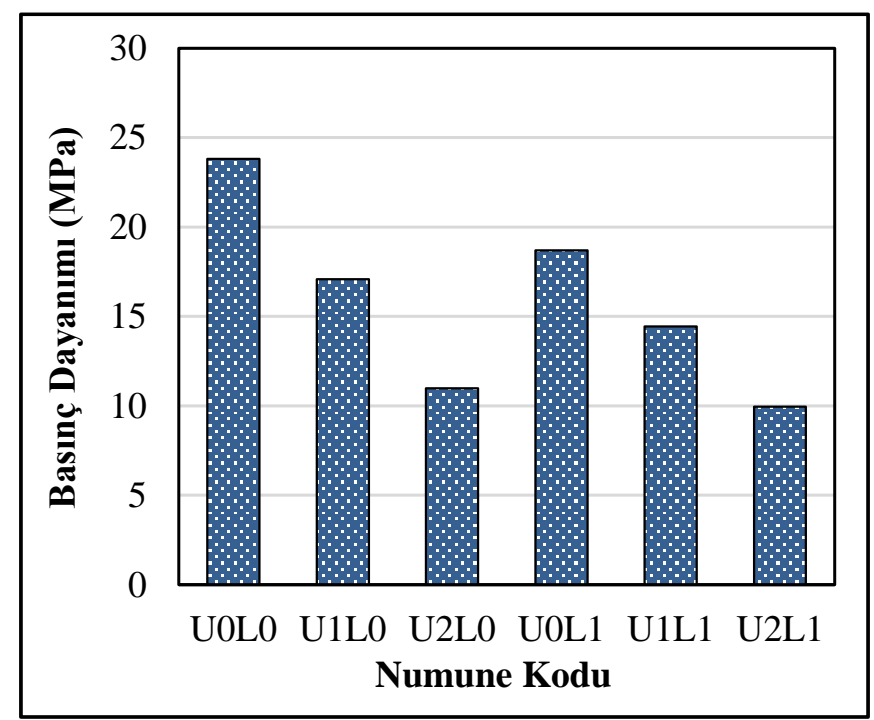

Şekil 6. Ĕ̈itim ve Deney Seti İçin Hazırlanmış Betonların Basınç Dayanım Ortalama Değerleri

\subsection{Makine Öğrenmesi ile Beton Basınç Dayanım Tahmini}

Beton numulerinden oluşturulan veri setindeki her bir görüntüye GLCM yöntemi uygulanarak öznitelikleri belirlenmiştir. GLCM ile bir görüntüdeki kontrast, farklılık, homojenlik, enerji, korelasyon ve açısal ikincil moment özniteliklerinin her birinden 4 özellik elde edilerek 4x6'lık bir öznitelik matrisi çıkarılmıştır. Daha sonra elde edilen matris KNN'de uygulanmak üzere vektörlere dönüştürülmüştür. Öznitelik vektörüne, betonun polipropilen lif durumu ve uçucu kül bilgisi eklenerek öznitelik bilgisi tamamlanmıştır.

Şekil 6 incelendiğinde UOL0 ve UOL1 kodlu betonların, U1L0 ve U1L1 kodlu betonların, U2L0 ile U2L1 kodlu betonların birbirine yakın basınç dayanım değerleri verdiği gözlemlenmiştir. $\mathrm{Bu}$ sebeple 3 farklı sınıf oluşturulmuştur. Sınıflardan ilki beton basınç dayanımları $23 \mathrm{MPa}$ 'dan yüksek olanlar, diğeri $23 \mathrm{MPa}$ ile $14 \mathrm{MPa}$ arasında bir değere sahip olanlar ve son olarak ise $14 \mathrm{MPa}$ değerinden düşük olanlar şeklinde sınıf bilgileri etiketlenmiştir.

Görüntü öznitelikleri KNN ile sınıflandırma yapabilmek amacıyla, eğitim ve test olarak 2 ayrı veri setine bölünmüştür. Görüntülerden rasgele seçilen \%80'i eğitim, geri kalan \%20'si ise test verisi olarak belirlenmiştir. K-NN algoritması PYTHON programlama dili üzerinde yazılmış, sklearn kütüphanesi ile kullanılmıştır. Yapılan deneyler ACER i5 8300H işlemcili, 16 GB RAM'e sahip bilgisayarda gerçekleştirilmiştir.

KNN algoritması ile sinıflandırma performansını belirleyebilmek için komşuluk sayıları ve örnekler arasındaki mesafe için kullanılan metrikler test edilmiştir. Algoritma 100 kez çalıştırılmış ve her iterasyonda eğitim ve test verileri tekrar rasgele seçilmiştir. Elde edilen doğruluk oranları Şekil 7'de gösterilmiştir. 


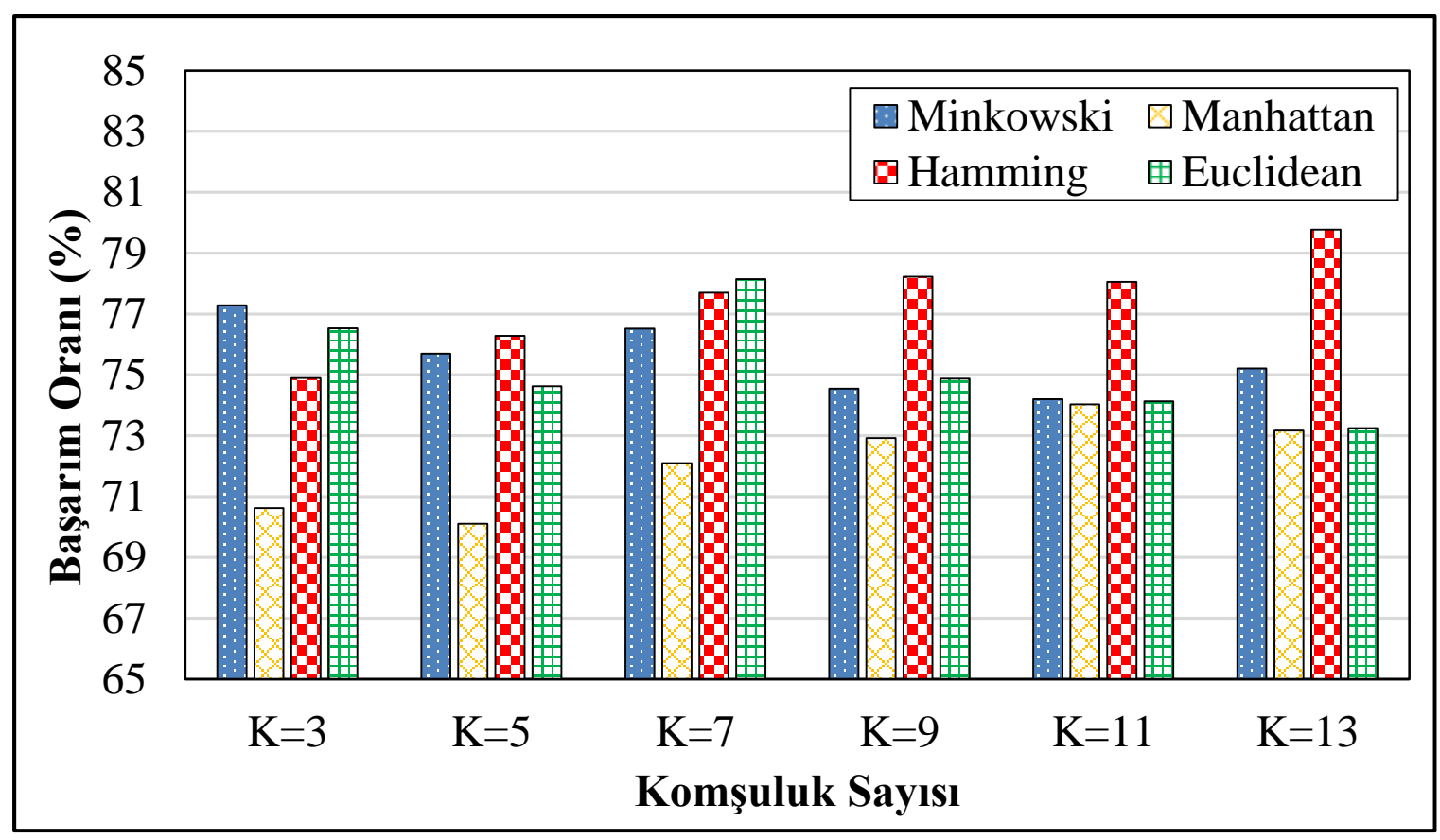

Şekil 7. KNN ile Elde Edilen Doğruluk Oranları

Yapılan deneyler sonucunda, Euclidean (Öklid) metriği kullanıldığında 100 'er defa yapılan testlerin ortalamasına göre komşuluk sayısı 7 seçildiğinde en yüksek başarıya ulaşılmıştır. Tahmin başarı oranı \%78,15 olarak gözlemlenmiştir. Manhattan metriğinde de aynı testler yapıldığında yine en yüksek başarıyı gösteren komşuluk sayısı bu sefer 11 iken, başarı \%74,03'te kalmıştır. Minkowski metriğinde, en iyi komşuluk sayısı 3 olarak gözlemlenmiştir. Başarı ise \%77,28 olarak ölçülmüştür. Yapılan çalışmada doğruluk oranının $\% 79,77$ ile en yüksek olduğu mesafe metriği Hamming mesafesi kullanılmıştır. Ayrıca komşuluk değeri 13 olarak belirlenmiştir.

KNN ile sınıflandırma başarımını ölçmek amacıyla Tablo 2'de gösterilen karışıklık matrisi 100 iterasyon sonunda oluşturularak doğruluk oranı haricinde duyarlılık ve özgünlük ölçütleri de kullanılmıştır.

Tablo 2. Karışıklık Matrisi

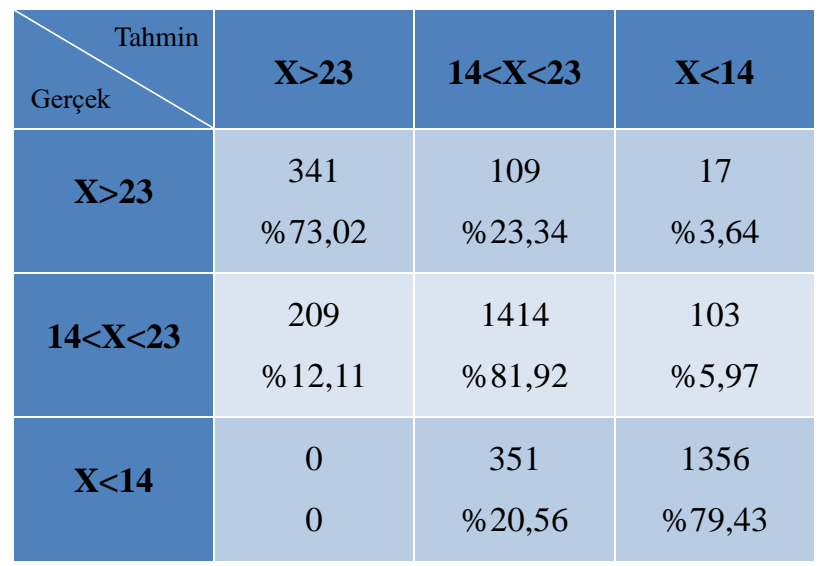

Duyarlılık ve özgünlük ölçütleri sırasıyla denklem 5 ve denklem 6'da gösterilmiştir.

$$
\begin{aligned}
& \text { Duyarlılık }=T P / P \\
& \text { Özgünlük }=T N / N
\end{aligned}
$$

Denklemlere göre duyarlılık 0.76 iken özgünlük değeri 0.79 olarak hesaplanmıştır. Sonuçlar irdelendiğinde algoritmanın, basınç dayanımları 23 değerinden büyük olan beton dayanım tahminlerini, diğer sınıflara oranla daha az oranla yapabildiği gözlemlenmiştir. Ayrıca algoritmanın, aynı su/çimento oranı, agrega, diatomit ve uçucu kül değerlerine sahip olan numune gruplarını tanıma başarısının yüksek olduğu sonucuna varılmaktadır. Elde edilen beton numunelerin üzerinde herhangi bir temizleme işlemi yapılmadan, sadece görüntüleri üzerinden ulaşılan dayanım tahminleri, betonun doğası gereği oldukça yüksek doğrulukta ölçülmüştür.

\section{Sonuç}

Teknolojinin hızla ilerlemesi ile makine öğrenmesi alanına ilgi her geçen gün artmaktadır. Makine öğrenmesi ile görüntü işleme metodu gelişen yeni teknolojilerde kullanımı hızla artmaktadır. Son dönemde hızla gelişen teknolojilerden bir tanesi de otomatik yap1 üretim teknolojisidir. Otomatik yap1 üretim teknolojisi, bilgisayar tabanlı sadece beton malzeme kullanan bir yöntemdir. $\mathrm{Bu}$ nedenle kullanılan betonun mekanik özellikleri konveksiyonel betonarme yapılara göre daha önemlidir. Betonun mekanik özelliklerinin başında ise basınç dayanımı gelmektedir. Basınç dayanımı önemli olan bu teknolojide, görüntüden basınç dayanımı tahmini yapmak kullanılan agrega boyutlarının küçük olması sebebi ile daha zordur.

$\mathrm{Bu}$ çalışmada otomatik üretime uygun betonların basınç dayanımları görüntü işleme yöntemleri kullanılarak belirlenmiştir. Beton görüntülerinin GLCM yöntemi ile öznitelikleri çıkarılarak KNN ile sınıflandırma işlemi gerçekleştirilmiştir. Yapılan deneyler sonucunda, beton basınç dayanım tahminlerinin önerilen yöntem ile yüksek oranda tanımlanabildiği gözlemlenmiştir. Gelecek çalışmalarda farklı öznitelik çıkarım yöntemleri ve makine öğrenmesi metotları kullanılarak tanıma oranlarının artırılması hedeflenmektedir. 


\section{Kaynakça}

Akhnoukh, A. K. (2020). Advantages of Contour Crafting in Construction Applications. Recent Patents on Engineering, 15(3), 294-300. doi: $10.2174 / 1872212114666200218111631$

Ayata, F. (2020). İçerik Tabanlı Görüntü Erişim Yöntemleriyle Aile Bireylerinde Yüz Tanıma Sistemi. Van yüzüncü Yıl Üniversitesi, Fen Bilimleri Üniversitesi Doktora Tezi.

Breysse, D. (2012). Nondestructive evaluation of concrete strength: An historical review and a new perspective by combining NDT methods. Construction and Building Materials, 33, 139-163. doi:10.1016/j.conbuildmat.2011.12.103

Chang, S., Cohen, T. and Ostdiek, B. (2018). What is the machine learning? Physical Review D, 97(5). doi:10.1103/PhysRevD.97.056009

Flah, M., Suleiman, A. R. and Nehdi, M. L. (2020). Classification and quantification of cracks in concrete structures using deep learning image-based techniques. Cement and Concrete Composites, 114. doi:10.1016/j.cemconcomp.2020.103781

Gibson, I., Rosen, D. and Stucker, B. (2015). Additive manufacturing technologies: $3 D$ printing, rapid prototyping, and direct digital manufacturing, second edition. Additive Manufacturing Technologies: $3 D$ Printing, Rapid Prototyping, and Direct Digital Manufacturing, Second Edition. doi:10.1007/978-1-49392113-3

Gul, J. Z., Sajid, M., Rehman, M. M., Siddiqui, G. U., Shah, I., Kim, K. H., ... Choi, K. H. (2018). 3D printing for soft robotics-a review. Science and Technology of Advanced Materials. doi:10.1080/14686996.2018.1431862

Hager, I., Golonka, A. and Putanowicz, R. (2016). 3D Printing of Buildings and Building Components as the Future of Sustainable Construction? Procedia Engineering in (Vol. 151, pp. 292-299). doi:10.1016/j.proeng.2016.07.357

Haralick, R. M., Dinstein, I. and Shanmugam, K. (1973). Textural Features for Image Classification. IEEE Transactions on Systems, Man and Cybernetics, SMC3(6), 610-621. doi:10.1109/TSMC.1973.4309314

Kabay, N. and Aköz, F. (2003). Yapıda beton kalitesinin tahribatlı ve tahribatsız yöntemlerle belirlenmesi. TMMOB Inşaat Mühendisleri Odası XVII.Teknik Kongresi in .

Kang, M. C., Yoo, D. Y. and Gupta, R. (2021). Machine learning-based prediction for compressive and flexural strengths of steel fiber-reinforced concrete. Construction and Building Materials, 266. doi:10.1016/j.conbuildmat.2020.121117

Kazemian, A., Yuan, X., Cochran, E. and Khoshnevis, B. (2017). Cementitious materials for construction-scale 3D printing: Laboratory testing of fresh printing mixture. Construction and Building Materials, 145, 639-647. doi:10.1016/j.conbuildmat.2017.04.015

Khorramshahi, M. R. and Mokhtari, A. (2017). Automatic construction by contour crafting technology. Emerging Science Journal, 1(1), 28-33. doi:10.28991/esj-201701113

Khoshnevis, B., Carlson, A., Leach, N. and Thangavelu, M. (2012). Contour crafting simulation plan for lunar settlement infrastructure buildup. Earth and Space 2012 Proceedings of the 13th ASCE Aerospace Division Conference and the 5th NASA/ASCE Workshop on
Granular Materials in Space Exploration in (pp. 14581467). doi:10.1061/9780784412190.155

Khoshnevis, Behrokh. (2004). Automated construction by contour crafting - Related robotics and information technologies. Automation in Construction in (Vol. 13, pp. 5-19). doi:10.1016/j.autcon.2003.08.012

Khoshnevis, Behrokh, Hwang, D., Yao, K. T. and Yeh, Z. (2006). Mega-scale fabrication by Contour Crafting. International Journal of Industrial and Systems Engineering, 1(3), 301320. doi:10.1504/IJISE.2006.009791

Khoshnevis, Behrokh, Thangavelu, M., Yuan, X. and Zhang, J. (2013). Advances in contour crafting technology for extraterrestrial settlement infrastructure buildup. AIAA SPACE 2013 Conference and Exposition in . doi: $10.2514 / 6.2013-5438$

Kim, C. N., Kawamura, K., Nakamura, H. and Tarighat, A. (2020). Automatic Crack Detection for Concrete Infrastructures Using Image Processing and Deep Learning. IOP Conference Series: Materials Science and Engineering in (Vol. 829). doi:10.1088/1757899X/829/1/012027

Kruger, J., Cicione, A., Bester, F., van den Heever, M., Cho, S., Walls, R. and van Zijl, G. (2020). Facilitating Ductile Failure of 3D Printed Concrete Elements in Fire. RILEM Bookseries in (Vol. 28, pp. 449-458). doi:10.1007/978-3030-49916-7_46

LaMonica, M. (2013). Additive Manufacturing-Innovations, Advances, and Applications. MIT Technology Review.

Leach, N., Carlson, A., Khoshnevis, B. and Thangavelu, M. (2012). Robotic construction by contour crafting: The case of lunar construction. International Journal of Architectural Computing, 10(3), 423-438. doi:10.1260/1478-0771.10.3.423

Li, M., Yang, B., Wang, L., Liu, Y., Zhao, X., Zhou, J. and Zhang, L. (2016). The prediction of cement compressive strength based on gray level images and neural network. 2016 3rd International Conference on Informative and Cybernetics for Computational Social Systems, ICCSS 2016 in (pp. 103-108). doi:10.1109/ICCSS.2016.7586432

Mahesh, B. (2020). Machine Learning Algorithms-A Review. International Journal of Science and Research, 9(1), 381386.

Mechtcherine, V., Grafe, J., Nerella, V. N., Spaniol, E., Hertel, M. and Füssel, U. (2018). 3D-printed steel reinforcement for digital concrete construction - Manufacture, mechanical properties and bond behaviour. Construction and Building Materials, 179, 125-137. doi:10.1016/j.conbuildmat.2018.05.202

Nazmul, I. M. and Matsumoto, T. (2008). High resolution COD image analysis for health monitoring of reinforced concrete structures through inverse analysis. International Journal of Solids and Structures, 45(1), 159-174. doi:10.1016/j.ijsolstr.2007.07.014

Özen, M. (2007). Investigation of relationship between aggregate shape parameters and concrete strength using imaging techniques. Doctoral Thesis. https://etd.lib.metu.edu.tr/upload/12608324/index.pdf from retrieved.

Parmar, H., Khan, T., Tucci, F., Umer, R. and Carlone, P. (2021). Advanced robotics and additive manufacturing of composites: towards a new era in Industry 4.0. Materials and Manufacturing Processes. doi:10.1080/10426914.2020.1866195 
Salet, T. A. M., Ahmed, Z. Y., Bos, F. P. and Laagland, H. L. M. (2018). Design of a 3D printed concrete bridge by testing*. Virtual and Physical Prototyping. doi:10.1080/17452759.2018.1476064

Shirooyeh, M., Vali, M., Shackleford, D., Torabi, P., Rehrig, P. W., Kwon, O. H. and Khoshnevis, B. (2015). Contour Crafting of Advanced Ceramic Terials. Advanced Processing and Manufacturing Technologies for Nanostructured and Multifunctional Materials II: A Collection of Papers Presented at the 39th International Conference on Advanced Ceramics and Composites January 25-30, 2015 Daytona Beach, Florida in (pp. 159168). doi:10.1002/9781119211662.ch18

Sinha, S. K. and Fieguth, P. W. (2006). Automated detection of cracks in buried concrete pipe images. Automation in Construction, 15(1), 58-72. doi:10.1016/j.autcon.2005.02.006

Sousa, J. P., Palop, C. G., Moreira, E., Pinto, A. M., Lima, J., Costa, P., ... Paulo Moreira, A. (2016). The SPIDERobot: A Cable-Robot System for On-site Construction in Architecture. Robotic Fabrication in Architecture, Art and Design 2016 in (pp. 230-239). doi:10.1007/978-3-31926378-6_17

Thompson, M. K., Moroni, G., Vaneker, T., Fadel, G., Campbell, R. I., Gibson, I., ... Martina, F. (2016). Design for Additive Manufacturing: Trends, opportunities, considerations, and constraints. CIRP Annals -
Manufacturing Technology, 65(2), 737-760. doi:10.1016/j.cirp.2016.05.004

Toklu, Y. C. and Çerçevik, A. E. (2017). Space research and extraterrestrial construction industry. Proceedings of 8 th International Conference on Recent Advances in Space Technologies, RAST 2017 in (pp. 11-15). doi:10.1109/RAST.2017.8002938

Toklu, Y. C., Çerçevik, A. E. and Şahinöz, M. (2016). Otomatik Yapı Üretim Teknolojisinde Kullanılabilecek Malzemelerin Belirlenmesi. Süleyman Demirel Üniversitesi Fen Bilimleri Enstitüsü Dergisi, 21(1), 51. doi:10.19113/sdufbed.73967

TS 1247. (2018). Beton Yapım, Döküm Ve Bakım Kurallar (Normal Hava Koşullarında).

Wiley, V. and Lucas, T. (2018). Computer Vision and Image Processing: A Paper Review. International Journal of Artificial Intelligence Research, 2(1), 22. doi:10.29099/ijair.v2i1.42

Yamaguchi, T. and Hashimoto, S. (2009). Practical image measurement of crack width for real concrete structure. Electronics and Communications in Japan, 92(10), 1-12. doi:10.1002/ecj.10151

Zhang, J. and Khoshnevis, B. (2013). Optimal machine operation planning for construction by Contour Crafting. Automation in Construction, 29, 50-67. doi:10.1016/j.autcon.2012.08.006 